\title{
A Look at the Digital Economy in Terms of Talent Using the LinkedIn Economic Graph
}

\author{
Yanping Wang
}

\begin{abstract}
Digital talent provides a unique perspective to study the global digital transformation and gain insights into the global digital economy. Trends like talent migration, hiring rates, and in-demand skills by region are focuses for LinkedIn and we are partnering with governments and non-governmental organizations around the world to share these insights and recommend policy solutions. In examining regional migration, we have found that China faces several challenges - an imbalance in the distribution of digital talent, lack of focus in digital talent cultivation and gender gaps in digital talent when hiring.
\end{abstract}

Keywords Digital talent - Digital transformation - Talent migration $\cdot$ Hiring rates - In-demand skills $\cdot$ Distribution of digital talent $\cdot$ Digital talent cultivation • Gender gaps

\section{Digital Talent, a Unique Perspective on the Global Digital Economy}

Breakthroughs in artificial intelligence, big data, and other new-generation information technologies have given the digital economy an increasingly important role in global economic growth. Countries everywhere around the world are using the digital economy to form the bedrock of their economic development.

In recent years, China's digital economy has witnessed accelerated development. The White Paper on China's Digital Economy Development (2020) released by the China Academy of Information and Communications Technology shows that in 2019, China's digital economy added value reached RMB 35.8 trillion, accounting for $36.2 \%$ of GDP. The digital economy has become a major engine that is prompting high-quality development in China's economy. Moreover, accelerating digital development and building a digital China have become top-priority national strategies outlined in the 14th Five-Year Plan and the 2035 Long-term Goal Outline released during China's Two Sessions.

Y. Wang $(\bowtie)$

LinkedIn China, Beijing, China 
Digital talent has become a key driving force behind the digital transformation of industries. As this transformation pushes forward, demand for digital talent is soaring. However, the supply gap for professional digital talent is still considerable. As a global talent platform, LinkedIn has over 740 million members, 55 million employers, 24 million open jobs, 36,000 skills, and 11,000 educational institutions. By mapping every member, company, job, and school, LinkedIn's data can uncover trends like talent migration, hiring rates, and in-demand skills by region. Partnering with governments and non-governmental organizations around the world to share these insights and recommend policy solutions, LinkedIn connects people to economic opportunities. Digital talent provides a unique perspective to study the global digital transformation and gain insights into the global digital economy.

\section{Millstones and Key Findings of Economic Graph Projects in China}

Since 2017, the LinkedIn China Economic Graph team has cooperated with the Center of Internet Development and Governance (CIDG) at Tsinghua University and has analyzed the development status of global digital talent and trends in the digital economy. Based on LinkedIn data, researchers looked at trends from perspectives including industry distribution, skill features, and mobility of talent. A total of seven reports on this topic were published over four consecutive years and have won attention and support from various sectors of society.

\subsection{Phase One (2017-2018)_-"Digital Talent" First Defined Under the LinkedIn Economic Graph}

The China Digital Economy Talent Report.

With more than 52 million members in China, LinkedIn has unique insights into the dynamics of China's digital talent landscape. In 2017, LinkedIn's Economic Graph team coordinated with Tsinghua University to launch the first-ever Economic Graph report on the digital talent landscape in China: The China Digital Economy Talent Report. In this report, the concept of "digital talent" was first defined as China's digital economy was just emerging.

The report identified the geographic distribution of digital talent in China, as represented by professionals with specific job titles that reflect "digital" functions. The functions were classified into six categories: digital strategy management, in-depth analytics, product $\mathrm{R} \& \mathrm{D}$, advanced manufacturing, digital operations, and digital marketing. These digital functions were found not just at companies in the tech industry, but increasingly in the manufacturing, finance, and consumer goods industries, too. Through this prism of "digital functions", we can assess the supply and 
demand of specific digital skills held by these professionals across industries and cities.

The flow of digital talent remains concentrated in first-tier cities, but the report found that China is in the midst of a digital transformation. The cities with the largest pools of digital talent were Shanghai, Beijing, Shenzhen, Guangzhou, and Hangzhou, while the cities of Chengdu, Suzhou, Nanjing, Wuhan, and Xi' an were close behind. With the exception of Guangzhou, several other first-tier cities showed a trend of gathering talent pools. Hangzhou and Suzhou have also become cities with a net influx of digital talent.

In terms of demand for digital talent, the most in-demand positions are concentrated in product R\&D and operations. Skill demand no longer focuses on programming, but more on comprehensive skills in technology, management, and leadership.

\section{The Understanding Migration Report}

With the Chinese economy becoming increasingly open through policies such as "the Belt and Road Initiative," China is transitioning from a talent exporter to a talent importer. Fifteen Chinese mainland cities_-including Beijing, Shanghai, Guangzhou and Shenzhen — saw significant international talent migration between January 2017 and February 2018. To better understand cross-regional talent migration patterns across industries, titles and skills, LinkedIn dove deeper into these trends and released its Understanding Migration Report in April 2018.

The most attractive cities are the most economically developed. This report found that despite the impact of factors such as geography and talent attraction policies, the majority of cross-regional talent migration is by professionals moving from the United States and the United Kingdom to Shanghai, Beijing, Shenzhen and Guangzhou. Emerging tier-one Chinese cities closely follow in terms of talent attraction from other regions.

By industry, cross-regional talent migration tends to align with regional economic strengths. In Hangzhou, for example, software and IT services attract most crossregional professionals, while professionals moving to Qingdao and Dongguan tend to relocate to work in manufacturing.

\subsection{Phase Two (2018-2019)—Regional Research on China's Digital Economy and Talent Development}

Digital Economy and Talent Development Report for China's Yangtze River Delta Region.

The rapid growth of China's digital economy across industries is driving socioeconomic mobility and is playing a critical role in regional economic development. 
To map the impact of digital transformation on China's regional economies, the LinkedIn Economic Graph team worked together with Tsinghua University and the Shanghai Institute of Science and Technology Policy to launch the Digital Economy and Talent Development Report for China's Yangtze River Delta Region in October 2018.

The report calculates the concentration of digital talent in 10 industries for major cities in the Yangtze River Delta Region, finding that ICT and manufacturing have the highest degree of digitization, and advantages vary in different cities (Fig. 1).

Five cities (Beijing, Shenzhen, Guangzhou, Wuhan, and Chengdu) are the top sources for domestic talent migration both into and out of the region. The report found that Hangzhou tops the list of most attractive cities for domestic digital talent, followed by Shanghai and Suzhou, while other cities are experiencing a net outflow of digital talent.

Shanghai plays an important role in developing talent to support other regions. It attracts more junior-level talent and exports more senior-level talent compared with other regions in China. This indicates that the city plays an important role in training
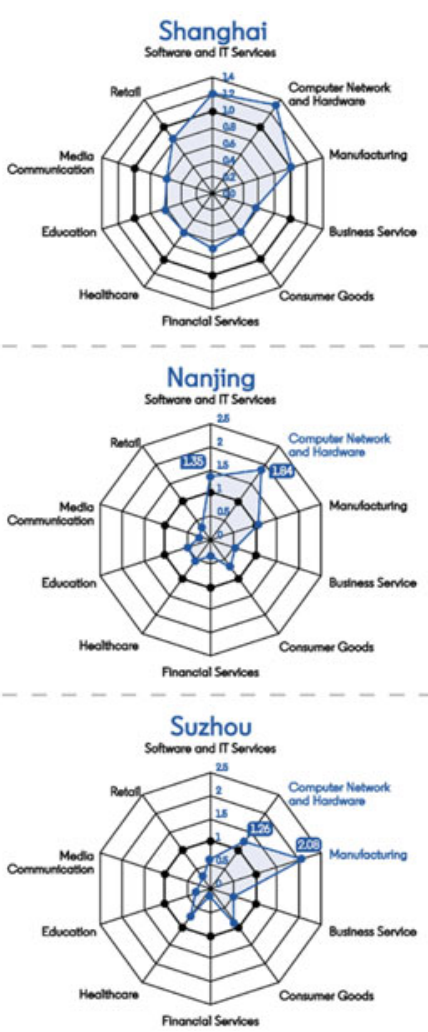
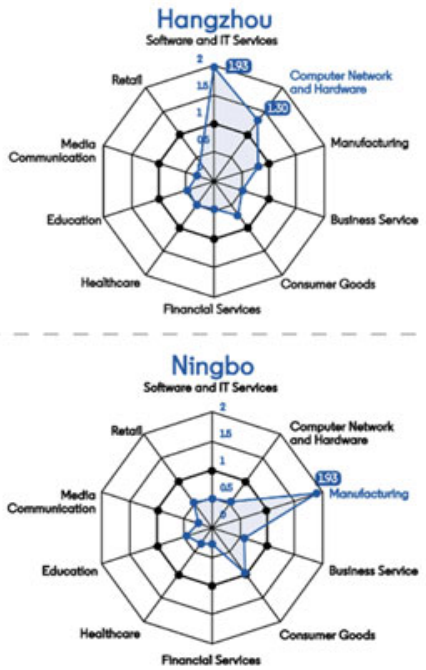

Hefei

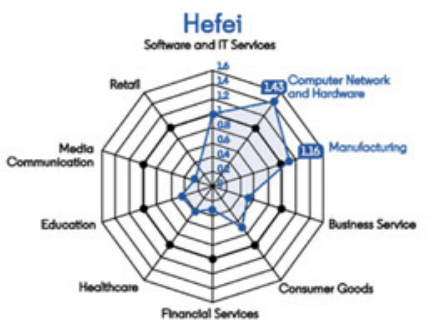

Fig. 1 Comparison of Digital Talent in Six Cities 
and developing talent, and it helps create a pipeline of digital talent for other regions (Fig. 2).

Digital Economy and Talent Development Report for Guangdong-Hong Kong-Macao Greater Bay Area.

As another of China's most economically developed regions with the highest level of reform and opening-up, the Guangdong-Hong Kong-Macao Greater Bay Area (also known as "the Greater Bay Area") has become a key player as China strives to build world-class city clusters and participates in global competition. With the progress of industrialization and IT application, the digital economy figures prominently in the GDP of the Greater Bay Area. In Feb 2019, the Digital Economy and Talent Development Report for Guangdong-Hong Kong-Macao Greater Bay Area was released in cooperation between the LinkedIn Economic Graph team and Tsinghua University.

Cities in the Greater Bay Area show distinctive characteristics in terms of industrial development. The report shows that Guangzhou features the most balanced talent distribution among industries; Shenzhen has outstanding talent advantages in ICT; Hong Kong boasts remarkable advantages in financial and educational talent;

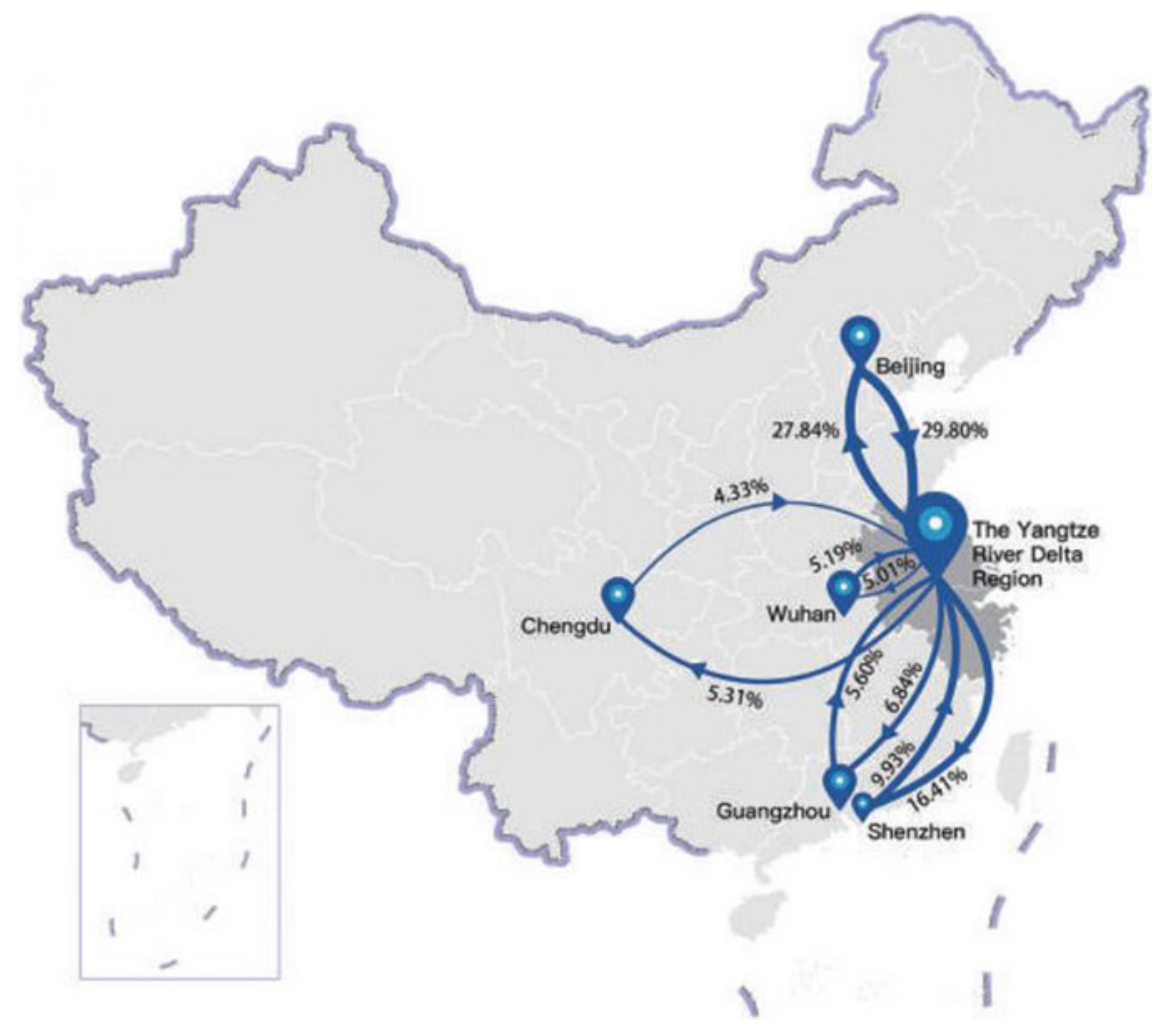

Fig. 2 Movement of Talent to and from the Yangtze River Delta Region 
and Macao has a very high concentration of digital talents in tourism and vacation services. The majority of talent in the other four cities in Guangdong province are concentrated mostly in manufacturing and consumer goods (Fig. 3).

It was also found that talent is concentrated more in the eastern part of the Greater Bay Area rather than the west, with the Pearl River as the dividing line. Top talent (BA and above) and digital talent were mainly found in Shenzhen, Hong Kong, and Guangzhou, while Shenzhen proved to be a top hub.

Moreover, the Greater Bay Area has an overall net inflow of talent. It is one of the most attractive hubs for digital talent in China with cities showing greater appeal than Beijing and Wuhan. It is also on par with Shanghai and Chengdu, but lag behind Hangzhou. From a global perspective, the Greater Bay Area holds some attraction for global talent, but this attraction can still be strengthened (Fig. 4).

These two well-developed regions in China have their own distinctive features. In the Yangtze River Delta Region, the driving roles of Shanghai and Hangzhou are prominent, while in the Greater Bay Area, cities complement each other with varied, distinctive features.
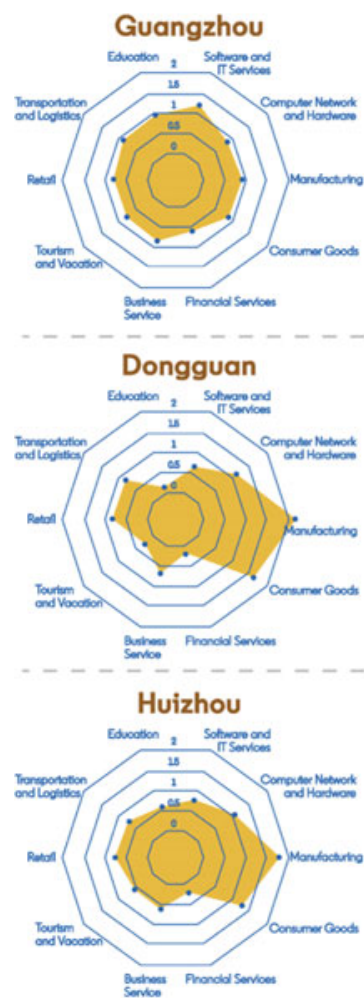
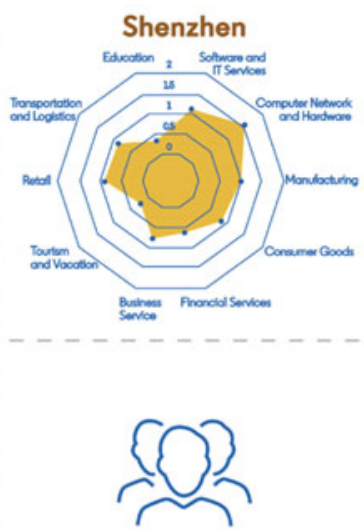

Digital Talents

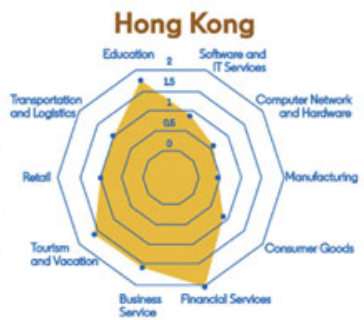

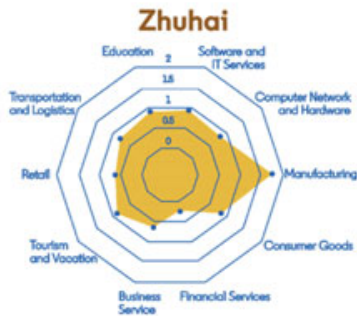

Foshan
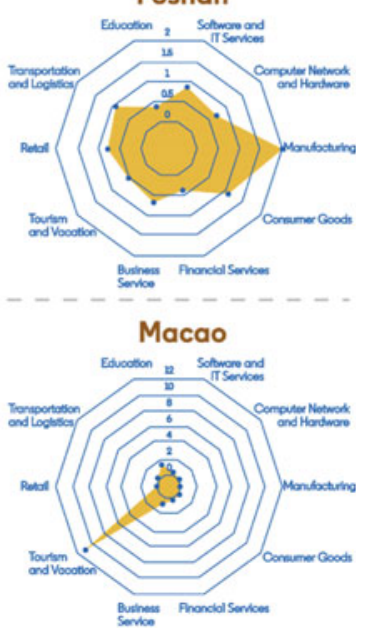

Fig. 3 Analysis of Cities in the Greater Bay Region 


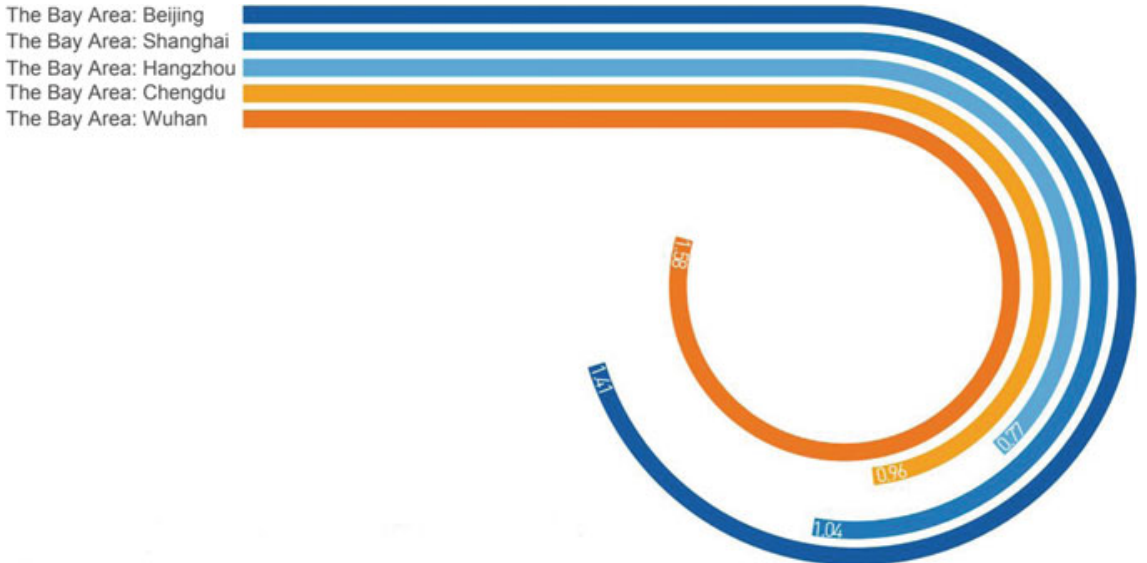

Fig. 4 Comparison of the Greater Bay Area to Other Cities in China

\subsection{Phase Three (2019-2020)—Deep Dive in Industry Concentrations of Global Digital Talent}

As the digital economy rapidly develops on a global scale, digitalization is affecting every aspect of the social economy and becoming a driving force for urbanization. Driving collaboration and innovation of traditional industries with digital technology and establishing regional and global innovation centers and world-class city clusters constitutes a new battlefield in global competitiveness.

Innovative Cities and City Clusters in the Era of Digital Economy: A Talent Perspective.

In searching for ways to unleash the potential of digital economy through talent strategies and drive the development of innovative cities and city clusters, LinkedIn China and Tsinghua SEM CIDG jointly released a collaborative report entitled Innovative Cities and City Clusters in the Era of Digital Economy: A Talent Perspective in November 2019. This report offered a global perspective with a comprehensive analysis of the digital talent status quo through an examination of employment, skill sets and the flow of digital talent across 11 city clusters world-wide.

The report showed that global digital talent frequently moves between cities, while Shanghai and Shenzhen were listed among the global top five in terms of talent attraction. Generally, the most frequent digital talent migration was between the Boston-Washington city cluster and the SF Bay Area, followed by migration between the Yangtze River Delta City Cluster, the Greater Bay Area City Cluster and the Triple $\mathbf{J}$ (Jing-Jin-Ji) City Cluster in China.

The SF Bay Area has a strong competitive edge in tech skills, while the Triple J (Jing-Jin-Ji) city cluster and YRD city cluster strong in disruptive tech skills. Based on LinkedIn's Skills Genome, this research calculated the relative penetration rate of tech skills and disruptive tech skills across 26 cities and observed that city 
clusters that have competitive advantages in both tech skills and disruptive tech skills include: Boston-Washington city cluster, SF Bay Area, UK-Ireland city cluster, Sydney Bay Area and Bangalore. City clusters that are competitive in disruptive tech skills include: the Germany city cluster, the Triple J (Jing-Jin-Ji) city cluster, the YRD city cluster, and Singapore (Fig. 5).

The proportion of digital talent in non-ICT industries is higher than in ICT industries overall. Among non-ICT industries, those with the highest proportion of digital talent are the manufacturing, finance, and consumer goods sectors.

\section{Global Digital Talent Index Report.}

To provide further insight into the migration of digital talent in major cities and regions around the globe, the LinkedIn Economic Graph broadened its scope to include 32 major cities around the world and published the 2020 Global Digital Talent Index Report under cooperation with Tsinghua SEM CIDG in October 2020.

The report further defines digital talent as individuals with skill sets relevant to the industry and excludes people with only simple digital literacy. Digital talent in the report includes strategy managers, high-end analysts, researchers, and developers. The report also incorporates talent with multiple digital skills, such as research and development, operations, smart manufacturing, and marketing.

The global proportion of digital talent in non-ICT industries is high, and the digital transformation of traditional industries continues to advance. The proportion of digital talent in non-ICT industries is higher than in the ICT industry, as digital transformation has integrated into all walks of life. Digital talent is concentrated in four major non-ICT industries: manufacturing, finance, consumer goods, and corporate services. Los Angeles, New York, Hong Kong, the United Arab Emirates, and London are the top five global markets with the highest proportion of digital talent in non-ICT industries (Fig. 6).

Digital skills are the most representative in emerging economies such as China and India. Beijing's representative skills are development tools, computer hardware, animation, digital marketing, and computer networking, while Shanghai's top-five skills are computer hardware, manufacturing operation, electronics, digital marketing, and foreign languages, as shown in this report.

Disruptive digital skills (e.g., AI, data science, robotics, etc.) are core to driving deeper digital transformation. Disruptive digital skills in North America, Europe, and the Asia-Pacific Region show differentiated development. North America leads the world in the penetration rate of disruptive skills; Europe's overall ranking is also high, with Munich taking the lead in aerospace and Paris in both aerospace and material science. In the Asia-Pacific Region, Bangalore, the UAE, and Singapore rank higher, while Chinese cities lag behind (Fig. 7). 


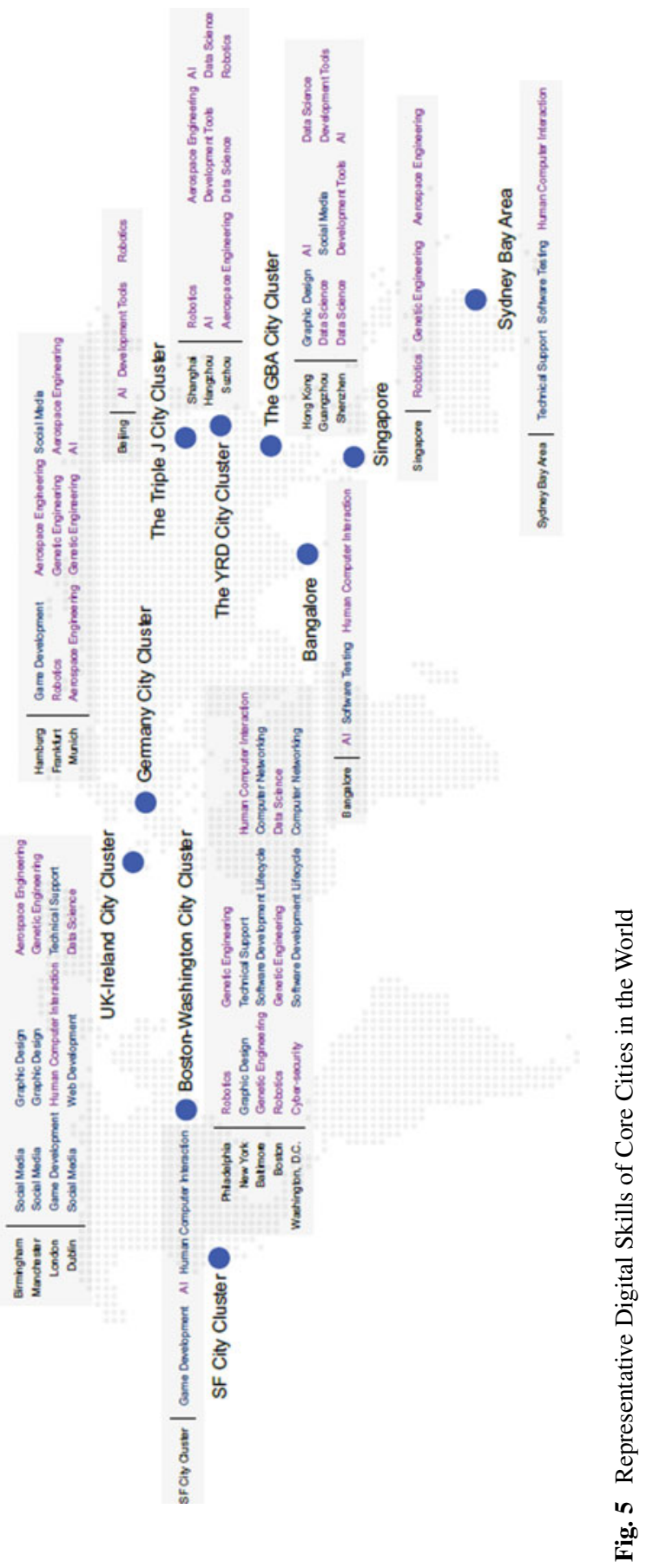




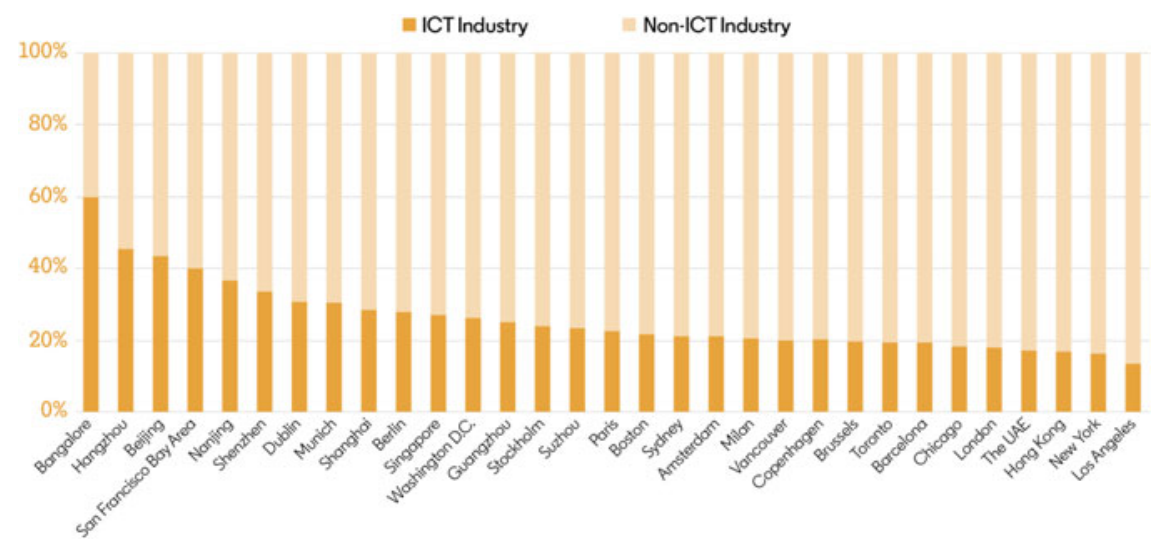

Fig. 6 Comparison of ITC/Non-ICT Industry Talent in Various Cities

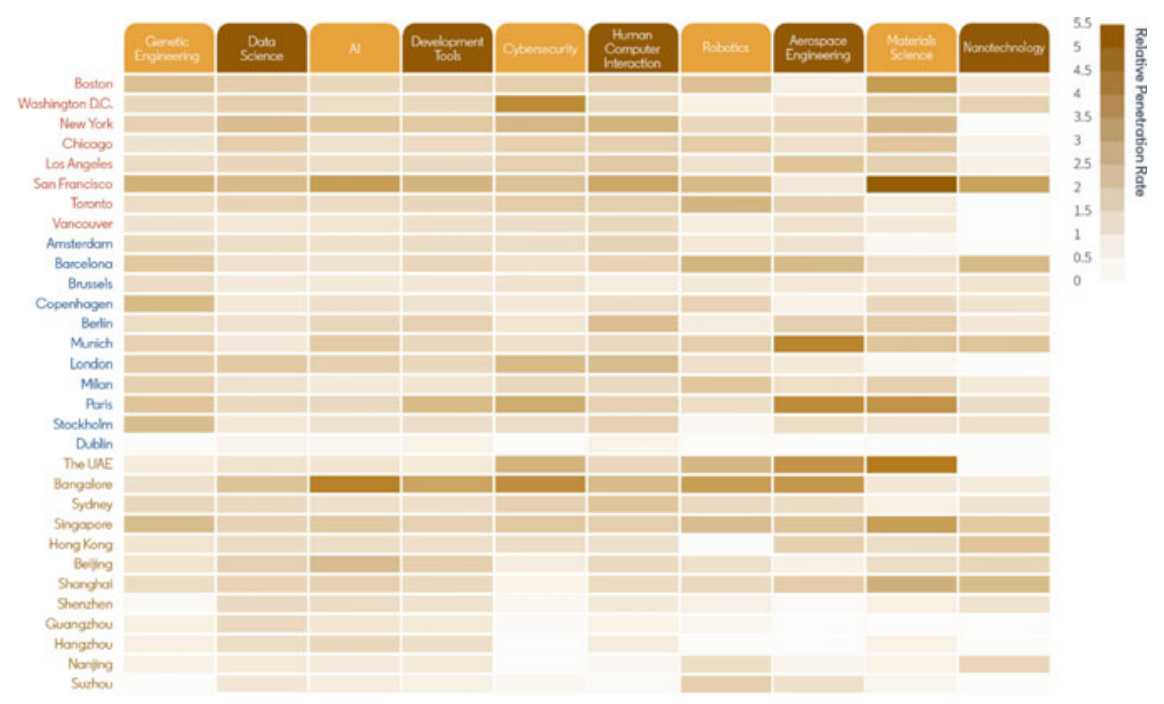

Fig. 7 Relative Penetration of Disruptive Digital Skills in Various Cities

\section{Observations and Policy Suggestions on Digital Talent}

\subsection{Distribution of Digital Talent is Unbalanced in China}

Digital talent is the main driving force behind the digital transformation of industries. As digital transformation pushes forward, the demand for digital talent is soaring, especially in the post-pandemic era when online industries are booming. However, 
China is facing a shortage of digital talent and a huge talent distribution gap exists between regions.

The cultivation of digital talent should keep up with the development of the digital economy. Therefore, the application of the "Dual Circulation Strategy" in the cultivation of digital talent could be a way out. On the one hand, it could strengthen the cultivation of domestic digital talent, while on the other hand, it could also make China more attractive to international digital talent. Attracting and retaining digital talent requires the consideration of various factors such as industrial foundations and innovative environments. Individual regions should attract digital talent by developing competitive industries, improving innovation ecosystems, and providing multi-faceted guarantee conditions like low taxes, high housing allowances, and open education/medical resources. These could attract talent and high-tech enterprises to these regions and balance the geographic gap in digital talent.

\subsection{Digital Talent Cultivation in the Post-Pandemic Era}

COVID-19 has posed both challenges as well as opportunities for the development and transformation of industries in China. Traditional industries such as manufacturing and consumer goods have witnessed a substantial negative shock, while industries such as online education, streaming media, and health care have seen more opportunities for further development due to their unique characteristics and growing market demand for their services. In the post-pandemic era, online professions like network anchors, online teachers, and We Media practitioners are emerging as online industries boom. Meanwhile, the app-oriented digital economy (e.g., Ali and Tencent apps) is making life more convenient and reshaping lifestyles. This has also been a good opportunity for traditional industries to start their own digital transformation. Therefore, a key issue that must be addressed is how to educate and train digital talent in traditional and emerging online industries.

Digital talent cultivation in the post-pandemic era should be more targeted, and an effective talent introduction and training mechanism should be established based on demand. Governments could give necessary guidance and training resources on practical demand of industrial digital transformation, and level a playing field for talent with different backgrounds.

\subsection{Skill is Becoming a New Currency in the Labor Market}

In July 2019, LinkedIn Economic Graph published a report titled Data Science in the New Economy: A New Race for Talent in the Fourth Industrial Revolution. In this report, the Skills Genome was revealed for the first time. It was found that skills can sensitively reflect tiny imbalances between supply and demand in the labor market and skill is becoming a new currency. 
Disruptive digital skills (e.g., AI, data science, robotics, etc.) are key to driving deeper digital transformation. Except for Shanghai, which has outstanding talent advantages in a few disruptive skill fields (materials science, nanotechnology and robotics), most cities in China still have huge potential for growth in terms of the penetration rate of disruptive skills, which also means great growth potential for China. We suggest learning from countries advanced in disruptive skills and strengthening skill cultivation in China.

At the China Development Forum held in March 2021, Chen Yubo, Associate Dean of the School of Economics and Management, Tsinghua University, said, "At present, the structural problems in China's digital talent pool are of clear. 95\% digital talent is concentrated in the R\&D and operation chains, and digital talents are flowing from traditional industries to the Internet and software industries." To further develop China's digital economy, we must optimize the demand structure of digital talent in China. Professor Chen suggests that we should strengthen the cultivation of disruptive skills and improve the cross-integration of digital skills and technologies such as biology, materials, and energy.

\subsection{Gender Gaps in Digital Transformation}

As the labor market recovers from the effects of the pandemic, the Global Gender Gap Report recently published by LinkedIn Economic Graph shows that women are being hired at a slower rate in multiple industries. It said that there has been a significant decline in women hired into leadership roles, effectively wiping out years of progress. Sectors with historically low representation of women are also those with fast-growing digital industries, such as cloud computing, where women make up $14 \%$ of the workforce, and engineering where it is only $20 \%$.

Sue Duke, Vice President, Head of Public Policy and Economic Graph at LinkedIn, said that "Women aren't well represented in the majority of fast-growing roles, which means we are storing up even bigger gender representation problems as we emerge from the pandemic. These roles play a significant part in shaping all aspects of technology and how it is deployed in the world. We simply have to have women's voices and perspectives represented at this foundational stage, especially as digitization is accelerating."

The report shed light on the growing gender gap in the global labor market under digital transformation. As one of the major parts of the global labor market, China would face the same challenges. Therefore, digital industries, especially futureshaping sectors like AI, cloud computing, big data, etc. should welcome more women. How to reduce gender gaps in these industries under the accelerating digital transformation is an issue that needs to be considered in China's future policymaking. 


\section{Afterword}

As the Chinese economy shifts from a stage of rapid growth to a stage of highquality development, data plays a huge role as a key factor of production. At present, China's Internet penetration rate exceeds the global average. With the largest number of Internet users in the world, China has become the world's largest Internet market and data resource. Thanks to this massive user bonus and rich application scenario, China's digital economy has seen rapid development over the past 20 years. China is now entering a new era and a developing digital economy. With the fields like electronic commerce, financial technology, and 5G communications leading the world, the international influence of China's digital economy is increasingly significant. There are multiple dimensions to study within China's digital economy, and the LinkedIn Economic Graph provides a unique talent perspective in the analysis of China's digital transformation. The insights offered in the reports can help employers, governments, and professionals understand the dynamics of their local, regional, or global labor markets, so as to create more economic opportunities for everyone. In the future, we will keep diving deep into research on China's digital economy and share more valuable information.

For more EG insights, please visit https://economicgraph.linkedin.com/resources.

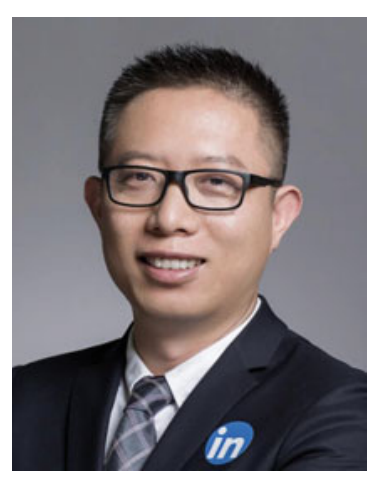

Yanping Wang serves as General Manager of China Public Affairs for LinkedIn, is responsible for developing and executing overall China policy strategy, leading LinkedIn's Economic Graph projects in China, and overseeing platform operational compliance team, content as well as customer service teams. Yanping also serves as Vice Chairman of the Sharing Economy Working Committee of the Internet Society of China; Executive Council Member of Center for China and Globalization; Council Member of China Society for Research on International Exchange and Talent Development; and Executive Council Member of China Association of Human Resource Development Intelligent Industry Branch. Before joining Silicon Valley internet, Yanping was the Vice President of Dangdang.com and Director of Public Affairs at Baidu. Yanping received his bachelor's degree from China Foreign Affairs University and his master's degree from University of International Business and Economics. 
Open Access This chapter is licensed under the terms of the Creative Commons AttributionNonCommercial-NoDerivatives 4.0 International License (http://creativecommons.org/licenses/bync-nd/4.0/), which permits any noncommercial use, sharing, distribution and reproduction in any medium or format, as long as you give appropriate credit to the original author(s) and the source, provide a link to the Creative Commons license and indicate if you modified the licensed material. You do not have permission under this license to share adapted material derived from this chapter or parts of it.

The images or other third party material in this chapter are included in the chapter's Creative Commons license, unless indicated otherwise in a credit line to the material. If material is not included in the chapter's Creative Commons license and your intended use is not permitted by statutory regulation or exceeds the permitted use, you will need to obtain permission directly from the copyright holder.

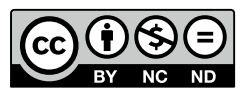

